\title{
BMJ Open Does suicide have a stronger association with seasonality than sunlight?
}

\author{
Richard A White, ${ }^{1}$ Deborah Azrael, ${ }^{2}$ Fotios C Papadopoulos, ${ }^{3}$ Gavin W Lambert, ${ }^{4,5}$ \\ Matthew Miller ${ }^{2}$
}

To cite: White RA, Azrael D, Papadopoulos FC, et al. Does suicide have a stronger association with seasonality than sunlight?. BMJ Open 2015:5:e007403.

doi:10.1136/bmjopen-2014007403

\section{- Prepublication history} and additional material is available. To view please visit the journal (http://dx.doi.org/ 10.1136/bmjopen-2014007403)

Received 8 December 2014 Revised 17 March 2015 Accepted 19 March 2015

\section{(1) cossuath}

\author{
${ }^{1}$ Norwegian Institute of \\ Public Health, Oslo, Norway \\ ${ }^{2}$ Department of Health \\ Sciences, Northeastern \\ University, Boston, \\ Massachusetts, USA \\ ${ }^{3}$ Department of \\ Neuroscience, Psychiatry, \\ Uppsala University, Uppsala \\ University Hospital, Uppsala, \\ Sweden \\ ${ }^{4}$ Human Neurotransmitters \\ Laboratory, Baker IDI Heart \\ and Diabetes Institute, \\ Melbourne, Australia \\ ${ }^{5}$ Central Clinical School, \\ Monash University, \\ Melbourne, Australia
}

Correspondence to Richard A White; rsands@bmjgroup.com

\section{ABSTRACT}

Objectives: Suicide rates have widely been reported to peak in spring and summer. A frequent hypothesis is that increased sunlight exposure alters biological mechanisms. However, few attempts have been made to systematically untangle the putative suicidogenic risk of sunlight exposure from that of seasonality. We examined whether average hours of daily sunlight in a month confer additional risk over month of year when predicting monthly suicide rates.

Design: Historical population-based ecological longitudinal study.

Setting and participants: We used 3 longitudinal studies ( $\mathrm{n}=31060$ suicides) with monthly suicide and meteorological data from Greece (1992-2001), Victoria, Australia (1990-1998) and Norway (19692009).

Intervention: We used a negative binomial regression to observe (1) the association of month of year with suicides, adjusting for different sunlight exposures, and (2) the association of sunlight exposure with suicides, adjusting for month of year. We then investigated claims that suicides were associated with daily sunlight exposures, defined by us as 2550 sunlight exposure combinations corresponding to a 1-50 days exposure window with lags of $0-50$ days.

Results: Using monthly data, the association between month of year and suicides remained after adjusting for mean daily hours of sunlight and change in the mean daily hours of sunlight. Adjusted for month of year, the associations between sunlight exposure and suicides became non-significant and attenuated towards the null (the coefficient estimate for mean daily hours of sunlight decreased in absolute magnitude by $72 \%$ ). The findings were consistent across all 3 cohorts, both when analysed separately and combined. When investigating daily sunlight exposures, we found no significant results after correcting for multiple testing.

Conclusions: Using monthly data, the robustness of our month of year effects, combined with the transient and modest nature of our sunlight effects, suggested that the association between sunlight exposure and suicide was a proxy for the association between seasonality and suicide.

\section{INTRODUCTION}

It has been noted broadly and frequently that suicides peak in spring and summer. ${ }^{1-11}$

\section{Strengths and limitations of this study}

We compared data from three markedly different countries at varying latitudes with different sunlight profiles in the northern and southern hemispheres.

- We analysed the data at both the monthly and daily aggregation levels.

- The sources of the sunlight exposure data were Melbourne, Athens and Oslo. The majority of the inhabitants of Victoria live in Melbourne $(74 \%$; 4.2/5.7 million); however, less numbers live in Athens (33\%; $3.7 / 11.2$ million) and Oslo (42\%; 2.1/5.0 million).

- The study only analyses suicides that have been documented in official registers, and might therefore miss a number of suicides that have been misclassified as undetermined deaths.

- The study does not investigate whether the same associations can be identified with attempted suicides as an outcome.

A frequent and plausible hypothesis to explain this relationship is that increased sunlight exposure alters biological mechanisms, possibly through the dysregulation of serotonin and/or melatonin production or metabolism. $^{1-9} 1213$

The vast majority of older studies focusing on sunlight exposure and suicide, however, either ignore seasonality (ie, the month of the year) or adduce seasonality as evidence of a positive relationship between sunlight and suicide. ${ }^{1-7} 9$ Lately, more studies apply seasonality corrections in their analyses, but still the results are inconclusive. Null, ${ }^{8}$ 14-17 beneficial, ${ }^{18-23}$ harmful $^{24} 25$ and mixed $^{26}$ associations have all been reported between sunlight and suicide after correcting for season. If sunlight exposure causes suicides in susceptible persons, then a relationship should still be observable after seasonality has been taken into account. Exceptionally bright summers should, for example, be more lethal than overcast summers (and, barring any existing threshold, dark winters should be more protective than sunnier 
winters), and vice versa. If such a suicidogenic relationship between sunlight and suicide were not present, then seasonality itself would remain related to suicide risk (with sunlight merely a very strong correlate of seasonality and confounder of the seasonality suicide relation).

The current study is the first to systematically attempt to disentangle the putative suicidogenic risk of seasonality from that of sunlight exposure using data from different sites with the same methodology. We do so by investigating within three cohorts (Greece: 1992-2001; Victoria, Australia: 1990-1998; Norway: 1969-2009) the relationship between month of year (shifted for concordance between the northern and southern hemispheres) and monthly suicide rates, and what attenuation, if any, occurs after adjusting for different measures of sunlight exposure. We then examine the relationship between monthly sunlight and suicides, and observe what attenuation, if any, occurs after adjustment for month of year. In addition, possible effect modification by season is investigated. Finally, we address concerns that monthly data are too crude to disentangle such associations by attempting to validate a new publication by Vyssoki $e t a l^{26}$ that identified positive (ie, harmful) and negative (ie, protective) associations between daily suicide rate and sunlight. Briefly, we investigate within two cohorts (Greece: 1992-2001; Victoria, Australia: 1990-1998) the relationship between daily suicide rate and daily sunlight exposure, after removing seasonality via differencing. For the daily analyses, we varied the daily sunlight exposure over 2550 sunlight exposure combinations corresponding to 1-50 days exposure window with lags of $0-50$ days, allowing us to investigate previous claims that suicide and suicidal attempts were associated with lagged sunlight exposures. ${ }^{25} 27$

The Victorian ${ }^{8}$ and Greek ${ }^{25}$ data have been examined previously to demonstrate the seasonality of suicides. Greece was found to have the highest seasonal suicide variation among 20 countries. However, prior analyses did not investigate the impact of adjusting for sunlight exposure on the seasonality of suicides, a crucial step in determining which of the following obtains: (1) sunlight exposure is related to suicides, while seasonality is not, (2) seasonality is related to suicides, while sunlight exposure is not, (3) both sunlight exposure and seasonality are separately related to suicides or (4) sunlight exposure is too closely correlated with seasonality to separate the associations. We investigated these four hypotheses in an exploratory manner, with the aim of determining which hypothesis had the most supporting evidence.

\section{MATERIALS AND METHODS}

We investigated three cohorts chosen by either contacting (1) authors who had published papers on suicide and seasonality after 2000 , or (2) those who had more than 10 years of suicide and meteorological data publicly available on a national government website. These detailed data sets contained the daily suicide rates in Greece (ICD9: E950-E959) from 1992 to 2001, Victoria, Australia (as defined by the coroner) from 1990 to 1998, and monthly suicide rates in Norway (ICD10: X60-X84, Y870) from 1969 to 2009. The Greek suicide data contained all suicides from January 1992 to December 2001, and were provided by the National Statistical Service of Greece, with daily data on solar radiance obtained from the National Observatory of Athens and then converted into approximate hours of sunlight using the Angstrom formula. ${ }^{28}$ The data set in the original Victorian study contained all suicides from January 1990 and April 1999; data from 1999 were excluded to ensure that we had equivalent monthly data for all years. Suicide data for Victoria were obtained from the Research and Information Coordination Group of the Office of the State Coroner of Victoria and the Victorian Institute of Forensic Medicine. Hours of bright sunlight (defined as the period of time during which the sun's intensity was sufficient to burn a trace on a standard chart when focused with a glass sphere; Campbell-Stokes recorder) were obtained from the Australian Bureau of Meteorology (station number 86071, Melbourne Regional Office). Norwegian suicide data from January 1969 to December 2009 were obtained from the Norwegian Cause of Death Registry through Statistics Norway, and hours of bright sunlight were obtained from the Norwegian Meteorological Institute for the Oslo-Blindern station.

When investigating the data aggregated at the monthly level (available from all three countries), we used two definitions of sunlight exposure: (1) the mean daily hours of sunlight in the month of interest (eg, on average, a day in June $2013 \mathrm{had} 4.5 \mathrm{~h}$ of sunlight), and (2) the change in mean daily hours of sunlight from the previous month (eg, on average, a day in June $2013 \mathrm{had}$ $4.5 \mathrm{~h}$ of sunlight, and a day in July 2013 had $5.7 \mathrm{~h}$ of sunlight, so the change in mean daily hours of sunlight was 1.2). Identical analyses were applied to both sunlight exposures.

Primary analyses examined the relationship between the monthly sex-specific suicide rate and seasonality in a pooled analysis of 948 sex-specific monthly observations; a negative binomial regression model (chosen due to the outcome being count data) was fitted with dummy variables for each month, adjusting for sex (sex set to 0.5 for Norwegian data to represent the 1:1, male:female sex ratio in Norway) and cohort. To observe the effect of adjusting for sunlight exposure, we then fit additional models that adjusted for (1) mean daily hours of sunlight and (2) change in mean daily hours of sunlight from the previous month.

To display the crude relationship between sunlight exposure and suicide, negative binomial regression models were fit in a pooled analysis of 948 sex-specific monthly observations, with the outcome of monthly sexspecific suicide rate, monthly sunlight exposures and adjustment for year, sex and cohort. Adjustment for 
month of year (seasonality) was then performed in a later model by including 11 months as dummy variables (February-December). These analyses were then rerun 12 times, each time restricting the data to a particular month to observe any potential effect of modification by season.

To account for the reversed seasons in the southern hemisphere, we recoded all months in Victoria to align with Greece and Norway (eg, January became July, February became August, and so on). We also adjusted the suicide rates for length of month in all analyses. We stress that these data were aggregated at the monthly level, so when investigating seasonality as defined using monthly indicators, our sunlight exposure data were also aggregated at the monthly level. However, we expressed our sunlight exposure data in terms of daily average to remove the issue of varying number of days in a month.

The above monthly analyses were rerun in substrata (as defined by all combinations of sex/cohort/month) as sensitivity analyses to ensure that the previously observed relationships were consistent and robust within sex, cohort and month. The results from these analyses are provided in the online supplementary materials.

In the hope of better addressing the hypothesis that 'an exceptionally bright summer will have a higher suicide rate', we calculated month-specific/cohortspecific Z-scores of the sunlight variables. In brief, for each month/cohort combination, we subtracted the mean and divided by the SD to generate a variable that represented variability from the mean. We then regressed suicides on the Z-scores, while adjusting for year, sex, cohort and month.

In order to address concerns that we were ignoring more nuanced associations, we decided to validate, in the data available to us, a recent study's claim that 'duration of daily sunshine was significantly correlated with suicide frequency independent of season. ${ }^{26}$, Owing to daily data requirements, only data from Greece and Victoria were used. Briefly, we differenced the outcome (daily suicide rate) and exposure (daily hours of sunshine) by taking the value on a given day and repeatedly subtracting the corresponding values of the corresponding days from 365 days previously, and then calculating the correlation between the two time series. We made two adjustments to the original method: first, we used the rate of suicides as the outcome instead of the crude numbers to account for population changes over time. Second, we applied a Bonferroni correction instead of using their described meta-testing: "First, it should be noted that with a significance level at $\mathrm{p}<0.001$, among 2550 correlations in figure 2 , on average only 2 or 3 significant coefficients are a result of type I error. Thus, the fact that many more values are significant in most of the graphs allows rejection of the null hypothesis that there are no correlations at all." We instead chose to use a Bonferroni correction as meta-testing overstates significance when used with positively correlated test statistics, ${ }^{29}$ which occurs here as many windows of sunlight overlap each other (eg, the results from an exposure from a time window of 230 days will be very similar to an exposure from a time window of 2-29 days). We otherwise faithfully applied the study's statistical methodology to our data, obtaining the correlation between

$$
\frac{1}{\mathrm{k}} \sum_{\mathrm{i}=1}^{\mathrm{k}} \mathrm{x}_{\mathrm{n}-1-\mathrm{k}^{\prime}} \bar{y}_{\mathrm{n}}
$$

where 1 indicates the time lag of 1 days between the averaged sunshine duration and day of suicide, and $\mathrm{k}$ the period of $\mathrm{k}$ days for which sunshine duration was averaged. $^{26}$

\section{RESULTS}

As historically noted, we found a strong association between month and sunlight exposure, with month explaining $87 \%, 78 \%$ and $79 \%$ of the variation in monthly sunlight exposure in Greece, Victoria and Norway, respectively (table 1 ).

We then considered data aggregated at the monthly level: across all countries and sexes, suicides rose in spring and summer and declined in autumn and winter (tables 1 and 2 and figure 1); after adjusting for different sunlight exposures, we found no systematic attenuation of the relationship in point estimates or significance (table 2). Furthermore, a likelihood ratio test concluded that the full model (including month and sunlight) was significantly different from a model without month variables (table 2). The unadjusted relationship between mean daily sunlight exposure and suicide revealed significant harmful relationships between mean daily sunlight exposure and suicide (incident rate ratio (IRR) $=1.018$; 95\% CI 1.012 to $1.0241 ; \mathrm{p}<0.001$ (table 3 ). After applying a simple adjustment for month, however, this relationship was noticeably attenuated towards the null and became non-significant $\quad(\mathrm{IRR}=0.995 ; 95 \%$ CI 0.984 to 1.007 ; $\mathrm{p}=0.44$ (table 3)). In other words, the effect of one extra mean daily hour of sunlight changed from significantly increasing the suicide rate by $1.8 \%$ to non-significantly decreasing it by $0.5 \%$, a change in absolute magnitude of $72 \%$. Furthermore, while a likelihood ratio test concluded that the full model (including month and sunlight) was not significantly different from a model without sunlight (table 3) (inferring that sunlight did not contribute to the full model), a likelihood ratio test concluded that the full model (including month and sunlight) was significantly different from a model without month (table 3) (inferring that month did contribute to the full model). Similar relationships were found when applying these analyses within cohort/sex strata (see online supplementary tables S1 and S2).

On examining pooled analyses stratified by month, in addition to further substratification by cohort/sex/ month combinations (77 tests), without adjusting for multiple comparisons, we identified only one significant 


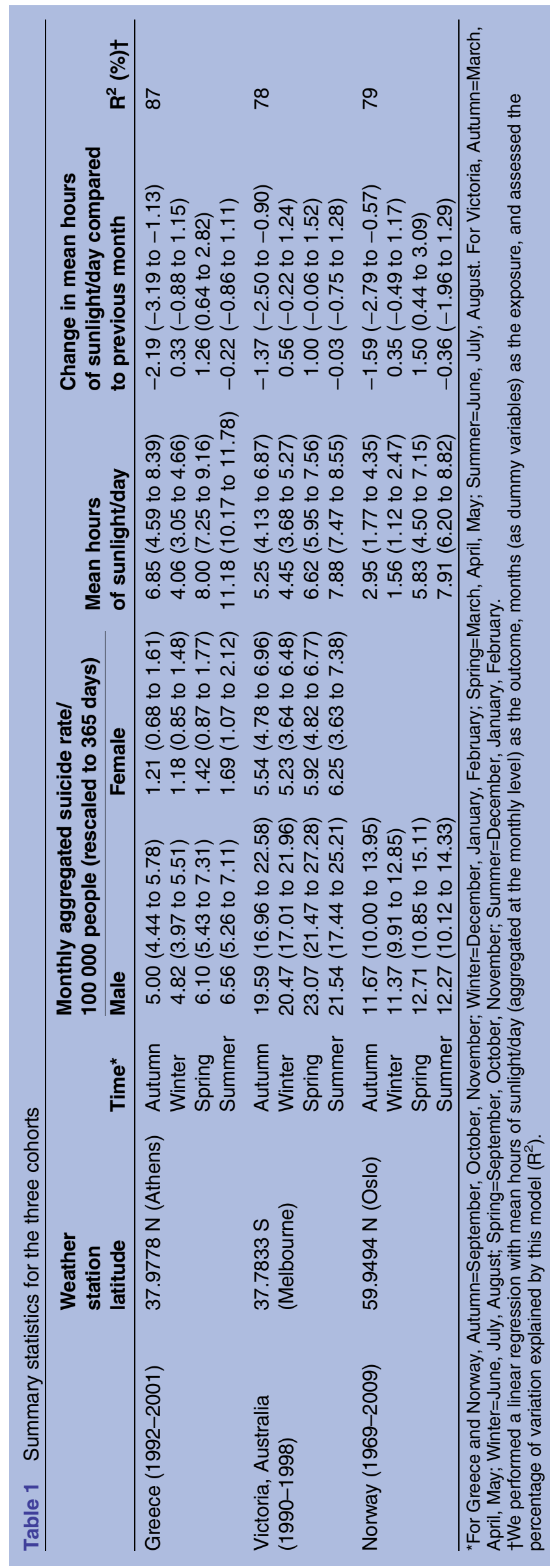

result: mean daily sunlight exposure was harmful for suicides in women in Victoria in February (see online supplementary table S2). We note that (in a situation where no association exists between an outcome and exposure) four false positives are expected when performing 77 tests at a $5 \%$ significance level $(77 \times 0.05=3.75)$.

The relationships between suicide, month of year and change in mean daily sunlight exposure from the previous month were substantively the same as when our measure of sunlight exposure was the mean daily sunlight exposure (see online supplementary tables S1-S3). The only noticeable deviation was that no significant results were found among the 77 additional sensitivity analyses.

When using monthly/cohort-specific Z-scores as sunlight exposures, we found that the seasonality variables were still significantly associated with suicide; however, the sunlight Z-scores were never significantly associated with suicide (see online supplementary tables S4 and S5).

When attempting to validate Vyssoki's ${ }^{26}$ findings using all-sex daily data in Victoria and Greece, we did not find any significant correlations between daily suicide rate and hours of daily sunshine after differencing for the effects of season and correcting for multiple testing (figure 2). Even without correcting for multiple testing, we did not find any conclusive evidence of a harmful association, and only minimal evidence of a protective association in Victoria (figure 2). Furthermore, our effect sizes were nominal, and the most extreme $p$ values were still far from reaching significance after correcting for multiple testing (see online supplementary figure S1).

\section{DISCUSSION}

When using monthly data, we found no evidence of a harmful relationship between sunlight exposure and suicides after adjusting for month of year (table 3). While adjusting for month of year removed the risk of sunlight exposure (table 3), adjusting for mean sunlight exposure and change in mean sunlight exposure from the previous month neither removed nor attenuated the relationship between month of year and suicide (table 2). These results were consistent across sexes and cohorts (see online supplementary tables S1-S3). The robustness of our seasonality effects, combined with the transient nature of our sunlight effects, led us to conclude that, when using monthly data, the association between sunlight exposure and suicide appeared to be a proxy for seasonality and suicide. We considered that our monthly level findings may be hiding more nuanced associations; however, we found no compelling evidence of associations between sunlight and daily suicide rates after removing seasonality (figure 2 ).

A previous study ${ }^{25}$ hypothesised that the transition from low levels of sunlight to higher levels might stimulate serotonin production, analogous to the purported receptor-level serotonin effect of beginning a regimen of 
Table 2 Incident rate ratio (IRR) of suicide by month compared with reference of July, adjusted for (1) no sunlight variables (2) mean hours of sunlight/day (aggregated at the monthly level) and (3) change in mean hours of sunlight/day compared with previous month (aggregated at the monthly level)

\begin{tabular}{|c|c|c|c|}
\hline Exposuret & Unadjusted $\ddagger$ & $\begin{array}{l}\text { Adjusted for mean } \\
\text { hours of sunlight/day } \S\end{array}$ & $\begin{array}{l}\text { Adjusted for change in mean } \\
\text { hours of sunlight/day compared } \\
\text { to previous monthๆ }\end{array}$ \\
\hline January & $0.95(0.89$ to 1.03$)$ & $0.93(0.84$ to 1.03$)++$ & $0.96(0.89$ to 1.03$)$ \\
\hline February & $0.97(0.90$ to 1.04$)$ & $0.95(0.86$ to 1.04$)$ & $0.96(0.89$ to 1.04$)$ \\
\hline March & $1.04(0.97$ to 1.12$)$ & $1.02(0.94$ to 1.11$)$ & $1.03(0.96$ to 1.11$)$ \\
\hline April & $1.11(1.03 \text { to } 1.19)^{\star \star}$ & $1.10(1.02 \text { to } 1.19)^{*}$ & $1.10(1.02 \text { to } 1.19)^{*}$ \\
\hline May & $1.17(1.08 \text { to } 1.25)^{\star \star \star}$ & $1.16(1.08 \text { to } 1.25)^{\star \star \star}$ & $1.15(1.07 \text { to } 1.24)^{\star \star \star}$ \\
\hline June & $1.07(0.99$ to 1.15$)+$ & $1.07(0.99$ to 1.15$)+$ & $1.06(0.99$ to 1.15$)++$ \\
\hline July (reference) & 1 & 1 & 1 \\
\hline August & $1.08(1.00 \text { to } 1.16)^{*}$ & $1.07(1.00$ to 1.16$)+$ & $1.08(1.00 \text { to } 1.16)^{*}$ \\
\hline September & $1.00(0.93$ to 1.08$)$ & $0.99(0.91$ to 1.07$)$ & $1.01(0.93$ to 1.09$)$ \\
\hline October & $0.98(0.91$ to 1.05$)$ & 0.96 (0.87 to 1.05$)$ & $0.99(0.91$ to 1.06$)$ \\
\hline November & 0.96 (0.89 to 1.03$)$ & $0.93(0.84$ to 1.03$)++$ & $0.97(0.90$ to 1.04$)$ \\
\hline December & $0.88(0.82 \text { to } 0.95)^{\star \star \star}$ & $0.85(0.77 \text { to } 0.95)^{\star \star}$ & $0.88(0.82 \text { to } 0.95)^{\star \star \star}$ \\
\hline \multicolumn{4}{|c|}{$\begin{array}{l}+p<0.10,++p<0.20,{ }^{*} p<0.05,{ }^{* *} p<0.01,{ }^{* * *} p<0.001 \text {. } \\
+ \text { Data from Australia were recoded to align with Greece and Norway (eg, January became July, February became August, and so on). } \\
\neq p \text { Value }<0.001 \text { for testing if all month variables could be removed without impacting the model (likelihood ratio test of cohort+year+sex } \\
+ \text { month vs cohort+year+sex). } \\
\$ p \text { Value }<0.001 \text { for testing if all month variables could be removed without impacting the model (likelihood ratio test of cohort+year+sex+sun } \\
+ \text { month vs cohort+year+sex+sun). } \\
\text { Ip Value }<0.001 \text { for testing if all month variables could be removed without impacting the model (likelihood ratio test of cohort+year+sex+sun } \\
\text { change+month vs cohort+year+sex+sun change). }\end{array}$} \\
\hline
\end{tabular}

antidepressant medication, with the behaviour-level effect of enabling suicidal action prior to a salubrious effect on mood, hence increasing suicide risk soon after initiating drug therapy. ${ }^{12}{ }^{13}$ If so, long-term sunlight exposure might reduce suicide risk even if the latter risk may increase shortly after initial exposure to higher levels of sunlight (such as when transitioning into spring from winter). We examined this admittedly highly speculative possibility in our analysis of the relation between suicide rates and the change in mean daily hours of sunlight from the previous month. After adjusting for month of year, we found no evidence of any relationship between transitioning from low sunlight to high sunlight and suicides (1) throughout the year or (2) in particular months (table 3 ).

Our findings point to the need to attend to which seasonal factors, apart from sunshine, may underlie the seasonal patterns observed for suicide. Suicide is a complex phenomenon where biological, cognitive and personalityrelated factors contribute to susceptibility, which in turn interacts with environmental and socioeconomic seasonal factors. ${ }^{30}$ In this context, alcohol consumption,
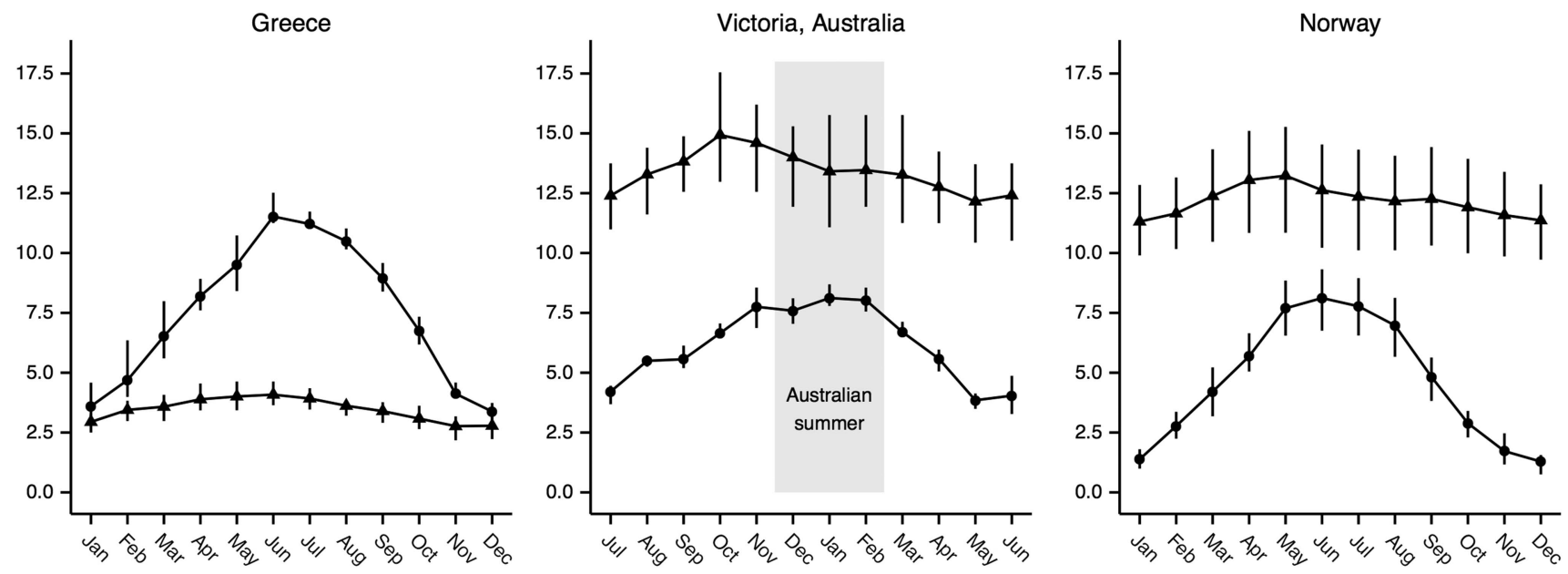

- Mean hours of sunlight per day $\Delta$ Suicide rate per 100,000 population

Figure 1 Suicide rate per 100000 population (rescaled to 365 days) and mean hours of sunlight per day for the three cohorts, summarised using a 3-month rolling average with error bars representing 25th and 75th centiles. 
Table 3 Suicide incident rate ratio (IRR) due to (1) an additional mean daily hour of sunlight (aggregated at the monthly level), and (2) an additional mean daily hour of sunlight compared with the previous month (aggregated at the monthly level)

\begin{tabular}{lll} 
Data restricted to & $\begin{array}{l}\text { IRR due to an additional mean } \\
\text { daily hour of sunlight }\end{array}$ & $\begin{array}{l}\text { IRR due to an additional mean daily hour } \\
\text { of sunlight compared with the previous month }\end{array}$ \\
\hline Entire year (not adjusted) & $1.018(1.012 \text { to } 1.024)^{* * *}$ & $1.014(1.007 \text { to } 1.022)^{* * *}$ \\
Entire year (seasonality adjusted) & $0.995(0.984$ to 1.007$) \ddagger \S$ & $1.005(0.996$ to 1.015$)$ I),†† \\
January & $1.014(0.950$ to 1.083$)$ & $1.018(0.969$ to 1.069$)$ \\
February & $1.013(0.968$ to 1.061$)$ & $1.001(0.957$ to 1.048$)$ \\
March & $0.982(0.945$ to 1.020$)$ & $0.996(0.966$ to 1.026$)$ \\
April & $0.978(0.939$ to 1.020$)$ & $1.012(0.981$ to 1.045$)$ \\
May & $1.010(0.977$ to 1.043$)$ & $1.003(0.978$ to 1.028$)$ \\
June & $0.989(0.959$ to 1.021$)$ & $0.996(0.972$ to 1.020$)$ \\
July & $0.992(0.953$ to 1.033$)$ & $1.021(0.995$ to 1.048$)++$ \\
August & $0.983(0.948$ to 1.018$)$ & $0.988(0.959$ to 1.018$)$ \\
September & $1.006(0.961$ to 1.052$)$ & $1.028(0.993$ to 1.064$)++$ \\
October & $0.980(0.923$ to 1.041$)$ & $0.986(0.952$ to 1.021$)$ \\
November & $0.978(0.907$ to 1.054$)$ & $0.999(0.954$ to 1.047$)$ \\
December & $0.979(0.922$ to 1.040$)$ & $1.002(0.954$ to 1.052$)$
\end{tabular}

$++p<0.20+p<0.10{ }^{*} p<0.05^{* *} p<0.01{ }^{* * *} p<0.001$.

†Data from Australia were recoded to align with Greece and Norway (eg, January became July, February became August, and so on). $\ddagger p$ Value $=0.44$ for testing if sunlight variable could be removed without impacting the model (likelihood ratio test of cohort+year+sex+sun +month vs cohort+year+sex+month).

$\S p$ Value $<0.001$ for testing if all month variables could be removed without impacting the model (likelihood ratio test of cohort+year+sex+sun +month vs cohort+year+sex+sun).

Ip Value $=0.25$ for testing if sunlight variable could be removed without impacting the model (likelihood ratio test of cohort+year+sex+sun change+month vs cohort+year+sex+month).

$\dagger+p$ Value $<0.001$ for testing if all month variables could be removed without impacting the model (likelihood ratio test of cohort+year+sex+sun change+month vs cohort+year+sex+sun change).

unemployment, work/holiday patterns, family support, drug use and seasonal variation in depression and psychoses are important risk factors for suicide and show a seasonal variation. Other meteorological and environmental factors, such as temperature and aeroallergens, also follow seasonal patterns and have been implicated in suicide. ${ }^{31-38}$

Several limitations should be borne in mind when interpreting our findings: we had concerns that the meteorological data might have been misclassified, due to measurements only occurring at a single location. However, Athens, Melbourne and Oslo/Akershus contain roughly $33 \%$ (3.7/11.2 million), $74 \%$ (4.2/5.7 million) and 42\% (2.1/5.0 million) of the inhabitants of their respective countries/states. When aggregating data at the monthly level, we believed that geographical differences would become even smaller. Finally, we repeated the Norwegian analysis, replacing the meteorological data with that of Bergen's (Norway's second largest city, located on a different coast), and found similar results (not shown). We did not have concerns that our null findings were due to limited power, as we applied pooled analyses in a large data set $(n=948$ sexspecific monthly observations, corresponding to 31060 suicides) comprising three countries, which (before adjustment) showed historically noted significant associations. While definitions of sunlight in Greece differed from those in other countries, the exposure was treated identically in the statistical analyses. We have no reason to suspect that our results were biased due to this, as our stratified analyses within Greece reflected the main analysis, as did the Z-score analyses (neither of which could be affected by differing definitions of sunlight).

To the best of our knowledge, our multisite study is the largest and most detailed on the relationship between sunlight and suicide that accounts for seasonality; previous studies have been limited by a singular geographic location, ${ }^{8}$ 14-18 22-25 lack of longitudinal data $^{19} 20$ or limited longitudinal data (only 2 years of data). ${ }^{21}$ Our study consisted, respectively, of 10 and 9 years of daily data from Greece and Victoria, and 41 years of monthly data from Norway, which enabled us to validate our aggregated findings and illuminate possible causal pathways through more detailed analyses. Our study was limited by the lack of detailed sexspecific monthly data in countries that had more extreme seasonal variation (Norway); however, our Victorian and Greek data sets did not suggest strong sex-specific associations between seasonality and suicide (see online supplementary table S1). Another area of concern was that while the Norwegian and Greek data came from national registers, the Victorian data were obtained from a state-level registry maintained by the Office of the State Coroner of Victoria. It may be that different nations and/or states have different case definitions for deaths classified as suicides. However, when analysed separately, our results remained consistent between Victoria, Greece and Norway (see online supplementary tables S1-S3), which reassured us against some of these concerns. Our study was also limited by only analysing suicides classified in official registers. 

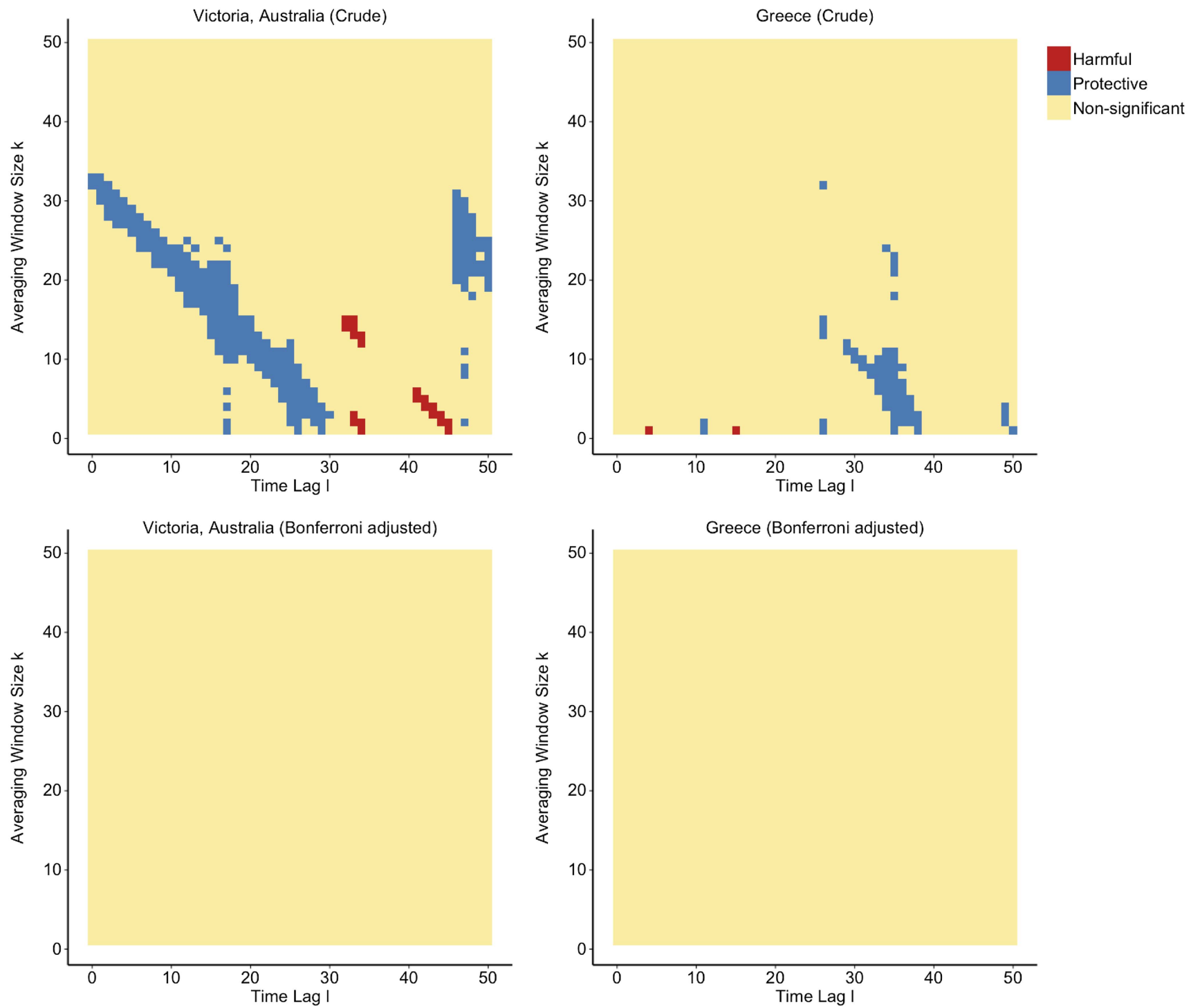

Figure 2 Correlation coefficients between duration of sunlight and daily suicide rate. Results presented both with and without corrections for multiple testing (Bonferroni).

An important sensitivity analysis would be to investigate if any associations could be found in undetermined deaths that might have been misclassified as suicides; however, we did not have access to these data. Future research should also be applied in investigating whether the associations we found hold true in suicidal acts in general (ie, attempted suicides plus suicides). Furthermore, future investigations should endeavour to investigate possible age interactions, as our inability to do so was a limitation of our study. We also note that our meteorological definition of sunlight exposure does not necessarily correspond to that which is perceived at the level of the eye. People spend time indoors, driving or are otherwise shaded from the sun, and these patterns may vary throughout the year (eg, indoors more during winter, driving during spring/ autumn, and wearing sunglasses and hats during summer). Our analyses stratified by month (tables 3, see online supplementary tables S2 and S3) provide evidence that our analyses (both combined and country-specific) are robust to seasonal patterns of sunlight avoidance/interference; however, future research efforts should strive to record sunlight exposure at a more individual level.

As far as we know, this study is the only one that explicitly examines both (1) the relationship between seasonality and suicides after adjusting for sunlight exposure and (2) the relationship between sunlight exposure and suicides, adjusted for seasonality. Furthermore, we applied analyses using both daily and monthly data, allowing for comparison of changing associations at different data aggregation levels. At the daily level, we saw no substantive evidence of an association between sunlight and suicides. At the monthly level, adjusted for seasonality (month of year), we found no evidence for sunlight exposure causing suicides (neither overall sunlight exposure, nor the transition from low sunlight exposure to high sunlight exposure). Instead, the 
historically noted relationship between seasonality and suicides remains after adjusting for mean hours of sunlight and change in mean hours of sunlight. Both analyses suggest that the seasonality of suicides, whatever the underlying mechanism may yet turn out to be, has incorrectly been attributed to sunlight exposure due to the strong correlation between seasons and sunlight.

Contributors RAW, DA and MM contributed to designing of the work. RAW, FP and GWL were involved in acquisition of the data. RAW contributed to analysis of the data. RAW, DA, FP, GWL and MM were involved in interpretation of the results. RAW, DA, FP, GWL and MM contributed to drafting of the manuscript. RAW, DA, FP, GWL and MM were involved in the final approval. The contributions of RAW, DA, FP, GWL, MM were accountable.

Funding This research received no specific grant from any funding agency in the public, commercial or not-for-profit sectors.

Competing interests The laboratory of GWL currently or recently received research funding from Medtronic, Abbott Pharmaceuticals, Servier Australia and Allergan. GWL has acted as a consultant for Medtronic and has received honoraria or travel support for presentations from Pfizer, Wyeth Pharmaceuticals, Servier and Medtronic.

Provenance and peer review Not commissioned; externally peer reviewed.

Data sharing statement The Norwegian data are freely available at http:// www.ssb.no and http://met.no/english/. We do not have approval to share the Greek/Australian data.

Open Access This is an Open Access article distributed in accordance with the Creative Commons Attribution Non Commercial (CC BY-NC 4.0) license, which permits others to distribute, remix, adapt, build upon this work noncommercially, and license their derivative works on different terms, provided the original work is properly cited and the use is non-commercial. See: http:// creativecommons.org/licenses/by-nc/4.0/

\section{REFERENCES}

1. Petridou E, Papadopoulos FC, Frangakis CE, et al. A role of sunshine in the triggering of suicide. Epidemiology 2002;13:106-9.

2. Maes M, De Meyer F, Thompson P, et al. Synchronized annual rhythms in violent suicide rate, ambient temperature and the light-dark span. Acta Psychiatr Scand 1994;90:391-6.

3. Preti A, Miotto P. Seasonality in suicides: the influence of suicide method, gender and age on suicide distribution in Italy. Psychiatry Res 1998;81:219-31.

4. Preti A. The influence of seasonal change on suicidal behaviour in Italy. J Affect Disord 1997;44:123-30.

5. Salib E. Elderly suicide and weather conditions: is there a link? Int J Geriatr Psychiatry 1997;12:937-41.

6. Salib E, Gray N. Weather conditions and fatal self-harm in North Cheshire 1989-1993. Br J Psychiatry 1997;171:473-7.

7. Souêtre E, Salvati E, Belugou JL, et al. Seasonality of suicides: environmental, sociological and biological covariations. J Affect Disord 1987; 13:215-25.

8. Lambert G, Reid C, Kaye D, et al. Increased suicide rate in the middle-aged and its association with hours of sunlight. $A m \mathrm{~J}$ Psychiatry 2003;160:793-5.

9. Vyssoki B, Praschak-Rieder N, Sonneck G, et al. Effects of sunshine on suicide rates. Compr Psychiatry 2012;53:535-9.

10. Christodoulou C, Douzenis A, Papadopoulos FC et al. Suicide and seasonality. Acta Psychiatr Scand 2012;125:127-46.

11. Woo J-M, Okusaga O, Postolache TT. Seasonality of suicidal behavior. Int J Environ Res Public Health 2012;9:531-47.
12. Lambert GW, Reid C, Kaye DM, et al. Effect of sunlight and season on serotonin turnover in the brain. Lancet 2002;360:1840-2.

13. Barton DA, Esler MD, Dawood T, et al. Elevated brain serotonin turnover in patients with depression: effect of genotype and therapy. Arch Gen Psychiatry 2008;65:38-46.

14. Tsai J-F, Cho W. Temperature change dominates the suicida seasonality in Taiwan: a time-series analysis. J Affect Disord 2012;136:412-18.

15. Hiltunen L, Suominen K, Lönnqvist J, et al. Relationship between day length and suicide in Finland. J Circadian Rhythms 2011;9:10.

16. Lin H-C, Chen C-S, Xirasagar S, et al. Seasonality and climatic associations with violent and nonviolent suicide: a population-based study. Neuropsychobiology 2008;57:32-7.

17. Ajdacic-Gross V, Lauber C, Sansossio R, et al. Seasonal associations between weather conditions and suicide-evidence against a classic hypothesis. Am J Epidemiol 2007;165:561-9.

18. Tietjen GH, Kripke DF. Suicides in California (1968-1977): absence of seasonality in Los Angeles and Sacramento counties. Psychiatry Res 1994;53:161-72.

19. Terao T, Soeda S, Yoshimura R, et al. Effect of latitude on suicide rates in Japan. Lancet 2002;360:1892-2.

20. Nishimura M, Terao T, Soeda S, et al. Suicide and occupation: further supportive evidence for their relevance. Prog Neuropsychopharmacol Biol Psychiatry 2004;28:83-7.

21. Souêtre E, Wehr TA, Douillet $P$, et al. Influence of environmental factors on suicidal behavior. Psychiatry Res 1990;32:253-63.

22. Yang AC, Tsai S-J, Huang NE. Decomposing the association of completed suicide with air pollution, weather, and unemployment data at different time scales. J Affect Disord 2011;129:275-81.

23. Ruuhela R, Hiltunen $L$, Venäläinen $A$, et al. Climate impact on suicide rates in Finland from 1971 to 2003. Int J Biometeorol 2009;53:167-75.

24. Müller H, Biermann T, Renk $\mathrm{S}$, et al. Higher environmental temperature and global radiation are correlated with increasing suicidality-a localized data analysis. Chronobiol Int 2011;28:949-57.

25. Papadopoulos FC, Frangakis CE, Skalkidou A, et al. Exploring lag and duration effect of sunshine in triggering suicide. J Affect Disord 2005;88:287-97.

26. Vyssoki B, Kapusta ND, Praschak-Rieder N, et al. Direct effect of sunshine on suicide. JAMA Psychiatry 2014;71:1231-7.

27. Kadotani $H$, Nagai $Y$, Sozu T. Railway suicide attempts are associated with amount of sunlight in recent days. J Affect Disord 2014;152-154:162-8

28. Sahin AD, Sen Z. Statistical analysis of the Angström formula coefficients and application for Turkey. Solar Energy 1998;62:29-38.

29. Schweder T, Spjøtvoll E. Plots of $p$-values to evaluate many tests simultaneously. Biometrika 1982;69:493-502.

30. Hawton K, van Heeringen K. Suicide. Lancet 2009;373:1372-81.

31. Williams A, While D, Windfuhr K, et al. Birthday blues: examining the association between birthday and suicide in a national sample. Crisis 2011;32:134-42.

32. Wu YW, Chen CK, Wang LJ. Is suicide mortality associated with meteorological and socio-economic factors? An ecological study in a city in Taiwan with a high suicide rate. Psychiatr Danub 2014:26:152-8.

33. Plöderl M, Fartacek C, Kunrath S, et al. Nothing like Christmas-suicides during Christmas and other holidays in Austria. Eur J Public Health 2015;25:410-13.

34. Volpe FM, Tavares A, Del Porto JA. Seasonality of three dimensions of mania: psychosis, aggression and suicidality. J Affect Disord 2008;108:95-100

35. McWilliams S, Kinsella A, O'Callaghan E. Daily weather variables and affective disorder admissions to psychiatric hospitals. Int $J$ Biometeorol 2014;58:2045-57.

36. Qin P, Waltoft BL, Mortensen PB, et al. Suicide risk in relation to air pollen counts: a study based on data from Danish registers. BMJ Open 2013;3:e002462.

37. Mann JJ. Neurobiology of suicidal behaviour. Nat Rev Neurosci 2003;4:819-28.

38. Li Z, Page A, Martin G, et al. Social science \& medicine. Soc Sci Med 2011;72:608-16. 


\section{Correction}

White RA, Azrael D, Papadopoulos FC, et al. Does suicide have a stronger association with seasonality than sunlight? BMJ Open 2014;4:e007403. The corresponding author email address was published incorrectly; the correct email address is: r.aubrey.white@ gmail.com

BMJ Open 2015;0:e007403. doi:10.1136/bmjopen-2014-007403corr1

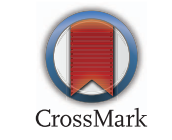

